\title{
EJNSO
}

\section{Thyroid scintigraphy indications based on clinical}

\section{experience}

\author{
Wafaa Abd Elhameed Elsayeed ${ }^{1}$, Rasha Abd Elhameed Ali ${ }^{2}$, Mona Elrabie \\ Ahmed ${ }^{3}$ Rafaat Abdelaal Bakheet ${ }^{1}$, and Megahed Mohamed Hassan ${ }^{3}$
}

1.Department of Clinical oncology and nuclear medicine department, Faculty of Medicine, Sohag University, Egypt

2.Public Health and Community Medicine, Faculty of Medicine, Sohag University, Egypt

3.Department of Phoniatrics, Otorhinolaryngology-Head and Neck Surgery, Sohag

University, Sohag, Egypt.

\begin{abstract}
:
Objective: Thyroid scintigraphy (TS) offers valuable information on thyroid anatomy and functional state of the gland. It is currently employed in both diagnosis and management of thyroid disorders. Data of 440 patients with thyroid disorders referred to thyroid scintigraphy at Sohag University Hospital has been analyzed in this study. Diagnostic contribution and indication of TS to thyroid disorders in adult and children have been assessed. Methods: It is a hospital-based cross-sectional descriptive study where all cases referred for TS at Sohag Institute Nuclear Medicine Unit from the $1^{\text {st }}$ of November 2015 to the $31^{\text {th }}$ of October 2018 were considered.

Results: Four hundred forty patients were referred to our unit with $84 \%$ female. The mean patient's age was 43.0 years. Sixty percent of the patients were referred for thyroid scan due to primary toxic goiter (Grave's disease), the second indication was post-thyroidectomy especially in differentiated thyroid cancer to estimate residual cancer thyroid and starting radioactive iodine treatment. Conclusion: Thyroid scintigraphy is an integral part of thyroid evaluation. However, it has been shown to be of small practical use in euthyroid patients with diffuse or multinodular goiters, or adult patients with hypothyroidism. It has great diagnostic and prognostic roles in congenital hypothyroidism. This emphasizes the importance of increasing the clinicians' awareness of TS when indicated and when not necessarily needed.

Keywords: Thyroid disorders; Thyroid scintigraphy; thyrotoxicosis; congenital hypothyroidism.
\end{abstract}

\section{Introduction}

Thyroid gland has a tremendously important role in regulating the metabolic functions like heart rate, cardiac output, lipid metabolism, heat regulation, and skeletal growth. In addition, it is markedly essential for the central nervous system (CNS) growth and maturation in infant and children. $^{1,2}$ Advances in thyroid imaging have improved diagnosis, treatment, follow-up, and prognosis of the thyroid diseases such as thyroid nodule, goiter, thyroiditis, and thyroid cancer. 
TS is one of the nuclear medicine procedures that produce a visual display of functional thyroid tissue depending on the selective uptake of various radionuclides by thyroid tissue. ${ }^{3,4}$ In addition to the morphological and anatomical information gained on the base of ultrasonography, TS pictures give qualitative and quantitative ideas on functional thyroid tissue. ${ }^{5}$ Consequently, the general indications for scintigraphy are wide including congenital hypothyroidism $(\mathrm{CH})$, thyrotoxicosis, and thyroiditis. Moreover, it is used to evaluate the extent of retrosternal goiter and ectopic thyroid (when ultrasound is incapable to visualize the lower pole of the thyroid gland). In the case of goiter without clear dominance of one nodule, scintigraphy is used to choose the biopsy site. ${ }^{6,7}$ Moreover, TS offers an extra technique for defining the qualified severity of thyroid disease that is less pretentious by the presence of concurrent non-thyroidal illness than laboratory evaluations. ${ }^{8}$

Thyroid scan plays a complementary role in diagnosis of hypothyroidism in infancy to confirm the underlying etiology. It detects patients who should be given lifelong replacement therapy (hypo plastic ectopic thyroid) and identified patients who need reevaluation (non-visualization or dyshormonogenesis). Ultrasound is less sensitive in detecting ectopic thyroid. However, TS detects ectopic foci of thyroid tissue. ${ }^{9}$

Actually, thyroid disorders are varying in diagnosis and treatment. We noticed that there is lack of awareness and incomplete information among clinicians and some surgeons with respect to scan benefits and indications.

Therefore, the objective of the current study is to analyze the scientific indications of TS based on the author's clinical experience.

\section{Patients and Methods:}

\section{Research design:}

The current research is a hospitalbased cross-sectional descriptive study where all cases referred for thyroid scintigraphy $99 \mathrm{mTc}$ scans in the Nuclear Medicine Unit at Sohag Institute Nuclear Medicine from the $1^{\text {st }}$ of November 2015 to the $31^{\text {th }}$ of October 2018 were included.

\section{Study instrument}

All referred patients underwent through routine evaluation protocol used in the Nuclear Medicine Unit, Cancer Institute, Sohag city, Egypt in accordance with the local institutional policy according to International Nuclear Medicine Procedure Guidelines for Thyroid Scintigraphy. The first step before scintigraphy is to collect history and medical information required for planning such as thyroid function tests results (TSH, Free T4 and possibly Free T3), previous and current medication, and results of other relevant investigations (e.g. ultrasound (US) and previous scintigraphy).

The procedure of TS using Tc $99 \mathrm{~m}$ includes imaging 20 minutes after the intravenous administration of $5-10 \mathrm{mCi}$ of $99 \mathrm{mTc} .{ }^{10}$

A scintillation camera equipped with parallel whole collimator is used. The camera setting is placed on the $140 \mathrm{keV}$ photo peak of $99 \mathrm{~m}$ Tc-pertechnetate, with a $10 \%$ window. Left and right anterior oblique images are obtained for 100000 to 300000 counts (or 5 minutes) each, the patient is supine, and the neck extended. ${ }^{11}$ The oblique images are important for the documentation of laterally and posteriorly placed nodules. These nodules could be missed in anterior images alone. Lead marker is placed at the sternal notch to assess the size of the thyroid gland. ${ }^{12}$ Typically, thyroid gland is symmetrical, and the lobes lateral borders are straight to convex. 
Tracer is normally seen in salivary glands and background. ${ }^{13}$ Certainly, TS is respected to diagnose the functional status of a nodule that may be 'hot' ,'warm' or 'cold' depending on whether the tracer uptake is greater than, equal to or less than the surrounding normal thyroid tissue respectively.

In $\mathrm{CH}, \mathrm{Tc}-99 \mathrm{~m}$ TS were recommended before beginning the treatment. However, this test in our region is not accepted by parents or even by some of pediatrician to be used especially before starting treatment. Thus, those children were assessed at their 3rd-4th years of age. Based on Tc-99m TS, the thyroid gland is classified as normal scan, ectopic, total agenesis, hemiagenesis, dyshormonogenesis, and athyrosis.

$\mathrm{CH}$ children were referred to the Phoniatric Unit at Sohag University to evaluate their language and cognitive abilities as follow: cognitive performance was evaluated by Stanford Binnet Intelligence Scale $5^{\text {th }}$ version for determination of intelligence quotient (IQ). Language skills were assessed by the standardized test and quantitative measures of communication difficulties, determined by age. Total language age deficit was calculated as the difference between the chronological age at the time of evaluation and the corresponding language age scores obtained at that time.

\section{Ethical considerations:}

Ethical approval for this study was obtained from ethical committee of the Faculty of Medicine, Sohag University. A written informed consent was obtained from the parent/caregiver of the children to participate in the study.

\section{Statistical analysis:}

Statistical Package for the Social Science (SPSS) program (version 20) was used for grouping, tabulation, and statistical analysis of the data. Sample characteristics were summarized using the mean and the standard deviation (SD) for continuous variables and percentage for categorical variables

\section{Results:}

Four hundred forty consecutive referrals were received over three years. The majority of patients scanned were female $(84 \%)$ versus $16 \%$ of male. The mean age was 43.0 years $(43.0 \pm 12.5)$ with range from 3-75 years. Thyroid function test, (TSH) was suppressed in $70 \%$ of patients and normal in $18 \%$ while $12 \%$ of patients had no blood results (Fig. 1).

\section{Thyroid Function Test}

- suppressed $\quad$ normal $\quad$ No blood results

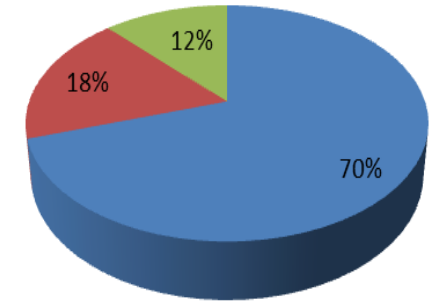

Figure 1: Shows the thyroid function test (TSH) among studied patients.

Patients were grouped according to the reason for scintigraphy as shown in figure (2). The highest percentage of the patients referred for TS were confirmed to have a primary toxic disease (Graves' disease) (60\%) followed by patients with after thyroidectomy. They mainly referred for detecting whether there is a sizable 
thyroid tissue residual that needs surgical completion or not $(23 \%)$. Five percent was a suspected nodule detected by clinical examination or sonar, multinodular goiter (4\%), goiter $(3 \%)$, thyroiditis $(3 \%)$ of patients. The lowest percentages were for congenital hypothyroidism $(2 \%)$.

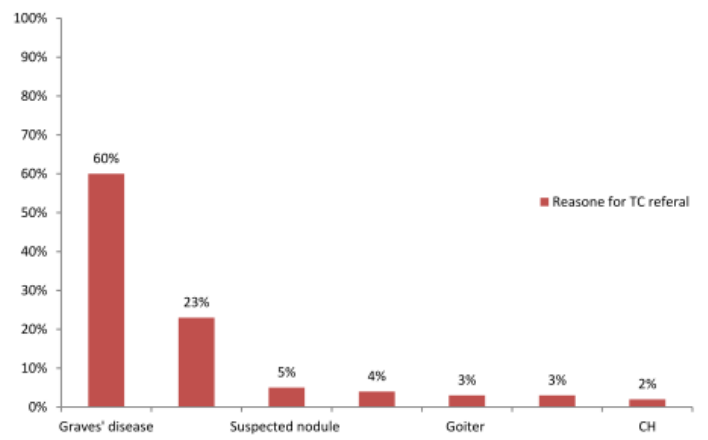

Figure 2: Distribution of the studied cases diagnosis

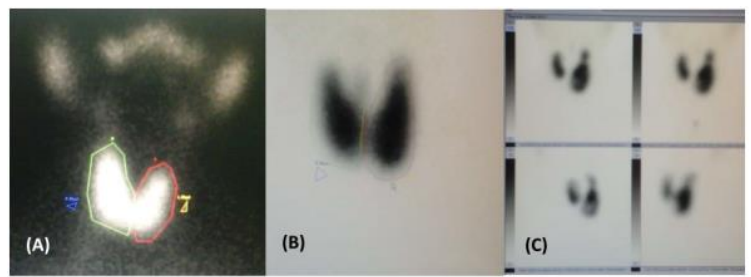

Figure 3: Show different types of thyroid disease as (A) shows goiter (B) Grave's disease with pyramidal lobe (C)Multinodular goiter.

Regarding to the $\mathrm{CH}$ findings on scan, there were three cases $(15 \%)$ diagnosed as thyroid hypoplasia, two cases (10\%) diagnosed as thyroid agenesia, one case (5\%) diagnosed as ectopic thyroid, and three cases $(15 \%)$ who were confirmed as transient $\mathrm{CH}$ had normal thyroid gland. The mean total language age deficit (year) and IQ values for each $\mathrm{CH}$ children according to the etiological finding by scan are shown in table (I).
Table1: Association between the language and cognitive abilities and the variables of $\mathrm{CH}$ etiology.

\begin{tabular}{|l|l|l|l|}
\hline \multicolumn{1}{|c|}{ CH Etiology } & $\%$ & $\begin{array}{c}\text { Total } \\
\text { Language } \\
\text { age deficit } \\
\text { (year) }\end{array}$ & Mean IQ \\
\hline Agenesia (N=2) & $10 \%$ & 2.75 & 45 \\
\hline Hypoplasia (N=3) & $15 \%$ & 0.7 & 69 \\
\hline Ectopia (N=1) & $5 \%$ & 0.5 & 73 \\
\hline $\begin{array}{l}\text { Transient } \mathrm{CH} \\
(\mathrm{N}=3)\end{array}$ & $15 \%$ & 0.2 & 97 \\
\hline
\end{tabular}

\section{Discussion :}

Thyroid gland is a hormonal secreting organ that regulates body metabolism. Thyroid gland diseases are a public health problem worldwide. Thyroid disorders can range from a small, harmless goiter (enlarged gland) that needs no treatment to life threatening diseases, such as thyroid cancer. $^{14}$ The commonest cause of thyroid disorders is iodine deficiency, almost one third of the world's population lives in the area of iodine deficiency. ${ }^{15}$

TSH serum level measuring is the most important and sensitive test for screening of thyroid disorders because serum TSH has a log linear relationship with circulating thyroid hormone levels; a twofold change in Free Thyroxin (FT4) will produce a 100 -fold change in TSH. Thus, serum TSH level is a necessary test for diagnosing a mild thyroid failure when the peripheral thyroid hormone levels are within normal laboratory range. ${ }^{16}$

The main objective of the existing study is to deliver a detailed descriptive data of all patients referred with thyroid complaints to the Nuclear Unit at Sohag Institute, Egypt over a period of 36 months. Analysis of the collected data would add in denoting indications of the referred thyroid scan in our unit.

$99 \mathrm{mTc}$ is most frequently used isotopes for thyroid scintigraphy as it is less expensive, more readily available, 
it requires less time. It has the benefit of a minor absorbed dose to the thyroid, so it permits the administration of higher doses and permits more rapid imaging.

In our institute, the majority of patients that were referred for TS are female (84\%) in agreement with previous studies. 17-19 The study conducted in Yemen in 2004 reported a higher prevalence of thyroid cancer in female than male. ${ }^{19}$

The majority of patients $(60 \%)$ refereed to our unit presented with biochemical evidence of hyperthyroidism and referred confirming Grave's disease. Grave's disease is one of the most common immune diseases that affects around $5 \%$ of the population and accounts for $50-80 \%$ of cases of hyperthyroidism. ${ }^{20}$ The main role of scintigraphy in thyrotoxicosis is to differentiate between hyperthyroidism with augmented thyroid uptake (Graves' disease, toxic nodular goiter), and hyperthyroidism associated with low thyroid uptake (thyroiditis), the treatment is diverse between these pathologies. In our study $60 \%$ of cases have high uptake more than $4.5 \%$ with picture of intense radiotracer uptake at both lobes of thyroid gland, decreased background activity, and low TSH referring to grave's disease. Thyroid scan has a great benefit in detecting Graves' disease even when hyperthyroidism presents without clinical signs suggesting Graves' disease. $^{21}$ Moreover, scintigraphy can indicate the presence of a solitary "cold" nodule within the diffuse toxic goiter that needs more work up to exclude malignancy. ${ }^{22}$ Autonomous nodules may appear hot or indeterminate and account for 5 to 10 $\%$ of palpable nodules. ${ }^{23}$

In this study, $23 \%$ of thyroid scans done for the post total-thyroidectomy patients to detect if there are any thyroid residual size and to determine the subsequent management. Actually, the thyroid gland cancer is among the most common endocrine cancer. 1.0 to $1.5 \%$ of all new cancers diagnosed each year in the USA is thyroid cancer. ${ }^{24}$ Based on recent data, thyroid cancer incidence has continuously increased in the last three decades all over the world $^{25}$ The causes for worldwide increase of thyroid cancer incidence are not clear. Some experts believe that the increased number of new cancers is due to the increased diagnostic intensity. ${ }^{26}$ Others believe that is a true increase linked to the environmental and lifestyle changes. ${ }^{27-}$ 28

Actually, role of TS in thyroid nodular disease is limited. US is preferred more to assess any suspicious features that would suggest non-benign pathology and used for guided fine needle aspiration and biopsy $\left(\right.$ FNAB) ${ }^{29}$

According to American Thyroid Association's guidance (ATA), TS only indicted if the solitary nodule presented with a low TSH "toxic solitary nodules". Previous studies showed that scintigraphy is highly beneficial in patients with toxic solitary nodule, ectopic thyroid tissue and retrosternal goiters. The routine use of thyroid imaging in patients with euthyroid goiters, hypothyroidism or suspected non-palpable nodules has been shown to provide little information beyond that would be obtained from careful clinical palpation. ${ }^{29,30}$

In infant, TS is an essential investigation for $\mathrm{CH}$. It is help identifying the underlying etiology of $\mathrm{CH}$, which is important in determining disease severity, outcome, and treatment schedules. TS can differentiate between hypoplasiaectopia, non-visualization and dyshormonogenesis. Thyroid 
hypoplasia confirmed when the radionuclide uptake is less, and a smaller gland is shown on US. However, thyroid agenesis is proved when both TS and US failed to visualize the gland. ${ }^{31,32}$ Patients with athyrosis have the greatest hormonal alteration and need a higher hormonal replacement dose as well as a closer monitoring. Additionally, diagnosis of transient hypothyroidism is important to avoid lifelong unnecessary therapy. 31-34

In the current study, the children with thyroid agenesis had higher occurrence of language deficit and lower IQ in comparison to other $\mathrm{CH}$ children with different etiologies, in agreement with previous studies. ${ }^{35-38}$ A previous study conducted with 100 children with $\mathrm{CH}$ and 100 children without the disease, reported that children with thyroid agenesis had a higher frequency of phonological deviation compared with those with other $\mathrm{CH}$ etiologies. ${ }^{37}$

\section{Conclusion:}

Thyroid Scintigraphy is a simple, non-invasive, cost effective tool for assessment of most thyroid disorders. If used properly it can response the queries that a clinician sitting in his clinic with a 'patient' and a 'thyroid profile/US/FNA report' needs to answer.

There is lack of awareness and incomplete information among clinicians regarding the scan benefits in congenital hypothyroidism. That emphasizes the need for planning strategies to increase clinicians' awareness as regard Thyroid Scintigraphy great benefits in congenital hypothyroidism.

Financial support and sponsorship: None

Conflicts of interest: There are no conflicts of interest.

\section{Reference:}

1. De Escobar GM, Obregón MJ, Del Rey FE. Role of thyroid hormone during early brain development. European Journal of Endocrinology. 2004 Nov 1;151(Suppl 3): U25-37.

2. Koromilas $\mathrm{C}$, Tsakiris $\mathrm{S}$, Kalafatakis K, Zarros A, Stolakis V, Kimpizi D, Bimpis A, Tsagianni A, Liapi C. Experimentally induced maternal hypothyroidism alters crucial enzyme activities in the frontal cortex and hippocampus of the offspring rat. Metabolic brain disease. 2015 Feb 1;30(1):241-6.

3. Chaudhary V, Bano S. Imaging of the thyroid: Recent advances. Indian journal of endocrinology and metabolism. 2012 May;16(3):371.

4. Wakeling J, Moore K, Elliott J, Syme H. Diagnosis of hyperthyroidism in cats with mild chronic kidney disease. Journal of small animal practice. (2008) 49(6), 287-294.

5. Dhingra VK. Nuclear scanning in evaluation and treatment of thyroid disorders: A beginners guide. Clinical Oncology. 2017; 2:1260.

6. Meller J, Becker W. The continuing importance of thyroid scintigraphy in the era of high-resolution ultrasound. European journal of nuclear medicine and molecular imaging. 2002 Aug 1;29(2): S42538.

7. Prasek K, Płazińska MT, Królicki L. Diagnosis and treatment of Graves' disease with particular emphasis on appropriate techniques in nuclear medicine. General state of knowledge. Nuclear Medicine Review. 2015;18(2):110-6.

8. Cooper DS, Doherty GM, Haugen BR, Kloos RT, Lee SL, Mandel SJ, Mazzaferri EL, McIver B, Pacini F, Schlumberger M, Sherman SI. Revised American Thyroid Association management guidelines for patients with thyroid nodules and differentiated thyroid cancer: the American Thyroid Association (ATA) guidelines taskforce on 
thyroid nodules and differentiated thyroid cancer. Thyroid. 2009 Nov 1;19(11):1167-214.

9. Schoen EJ, Clapp W, To TT, Fireman BH. The key role of newborn thyroid scintigraphy with isotopic iodide (123I) in defining and managing congenital hypothyroidism. Pediatrics-English Edition. 2004 Dec 1;114(6): e683.

10. Ghanem MA, Elgazzar AH, Elsaid MM, Shehab F. Comparison of pinhole and high-resolution parallelhole imaging for nodular thyroid disease. Clinical nuclear medicine. 2011 Sep 1;36(9):770-1.

11. Mettler Jr FA, Guiberteau MJ. Essentials of Nuclear Medicine Imaging: Expert Consult-Online and Print. Elsevier Health Sciences; 2012 Jan 11.

12. Dhingra VK. Nuclear scanning in evaluation and treatment of thyroid disorders: A beginners guide. Clinical Oncology. 2017; 2:1260.

13. Prasek K, Płazińska MT, Królicki L. Diagnosis and treatment of Graves' disease with particular emphasis on appropriate techniques in nuclear medicine. General state of knowledge. Nuclear Medicine Review. 2015;18(2):110-6.

14. Ratini M. Understanding Thyroid Problems-the Basics: Women's Health. WebMD Medical Reference, WebMD, LLC. View. 2015.

15. Zimmermann MB. Iodine deficiency. Endocrine reviews. 2009 Jun 1;30(4):376-408.

16. Casey BM, Dashe JS, Wells CE, McIntire DD, Byrd W, Leveno KJ, Cunningham FG. Subclinical hypothyroidism and pregnancy outcomes. Obstetrics \& Gynecology. $2005 \quad$ Feb 1;105(2):239-45.

17. Tindall H, Griffiths AP, Penn ND. Is the current use of thyroid scintigraphy rational? Postgraduate medical journal. 1987 Oct 1;63(744):869-71.

18. Nasheiti NA. Childhood hypothyroidism in IRAQ: a retrospective study. International
Journal of Endocrinology and Metabolism. 2005 Jan 1;3(3):136-9.

19. Abdulmughni YA, Al-Hureibi MA, Al-Hureibi KA, Ghafoor MA, AlWadan AH, Al-Hureibi YA. Thyroid cancer in Yemen. Saudi medical journal. 2004;25(1):55-9.

20. Bahn RS, Burch HB, Cooper DS, Garber JR, Greenlee MC, Klein I, et al. Hyperthyroidism and other causes of thytotoxicosis: Management guidelines of the American Thyroid Association and American Association of clinical endocrinologist Endocr Pract 2011;17:456-520.

21. Intenzo CM, De papp AE, Jabbour S, Miller j, Kim SM, Cappuzi CM. scintigraphic manifestations of thyrotoxicosis, Radiographics 2003;23:857-868.

22. Becker D, Charkes ND, Dworkin H, Hurley J, McDougall IR, Price D, Royal H, Sarkar S. Procedure guideline for thyroid scintigraphy: 1.0. Journal of Nuclear Medicine. 1996 Jul 1;37(7):1264-6.

23. Haugen BR, Alexander EK, Bible KC, Doherty GM, Mandel SJ, Nikiforov YE, Pacini F, Randolph GW, Sawka AM, Schlumberger M, Schuff KG. 2015 American Thyroid Association management guidelines for adult patients with thyroid nodules and differentiated thyroid cancer: the American Thyroid Association guidelines task force on thyroid nodules and differentiated thyroid cancer. Thyroid. 2016 Jan 1;26(1):1-33.

24. Curado MP, Edwards B, Shin HR, Storm H, Ferlay J, Heanue M, Boyle P. Cancer incidence in five continents, Volume IX. IARC Press, International Agency for Research on Cancer; 2007.

25. Jemal A, Siegel R, Xu J, Ward E. Cancer statistics, 2010. CA: a cancer journal for clinicians. 2010 Sep;60(5):277-300.

26. Grodski S, Brown T, Sidhu S, Gill A, Robinson B, Learoyd D, Sywak M, Reeve T, Delbridge L. Increasing incidence of thyroid cancer is due to increased 
pathologic detection. Surgery. 2008 Dec 1;144(6):1038-43.

27. Simard EP, Ward EM, Siegel R, Jemal A. Cancers with increasing incidence trends in the United States: 1999 through 2008. CA: a cancer journal for clinicians. 2012 Mar;62(2):118-28.

28. Aschebrook-Kilfoy B, Ward MH, Sabra MM, Devesa SS. Thyroid cancer incidence patterns in the United States by histologic type, 1992-2006. Thyroid. 2011 Feb $1 ; 21(2): 125-34$.

29. Tamhane S, Gharib H. Thyroid nodule update on diagnosis and management. Clin Diabetes Endocrinol. 2016; 2: 17 . doi: 10.1186/s40842-016-0035-7

30. Khanzada TW, Memon W, Kumar B, Samad A. Thyroid scintigraphy: An overused investigation. Gomal Journal of Medical Sciences 2009;7(1):39-41.

31. Connelly JF, Coakley JC, Gold H, Francis I, Mathur KS, Rickards AL,Price GJ, Halliday JL, Wolfe R. Newborn screening for congenital hypothyroidism, Victoria, Australia, 1977-1997. Part 1: The screeningprogramme, demography, baseline perinatal data and diagnosticclassification. J Pediatr Endocrinol Metab 2001; 14:15971610.

32. Schoen EJ, Clapp W, To TT, Fireman BH. The key role of newborn thyroid scintigraphy with isotopic iodide (123I) in defining and managing congenital hypothyroidism. Pediatrics 2004;114: e683- 688.

33. Sfakianakis GN, Sfakianaki E, Georgiou M, Serafini A, Ezuddin S, Kuker R, Zilleruelo G, Strauss J, Abitbol C, Chandar J, Seeherunvong W. A renal protocol for all ages and all indications: mercapto-acetyl-triglycine (MAG3) with simultaneous injection of furosemide (MAG3-F0): a 17-year experience. InSeminars in nuclear medicine 2009 May 1 (Vol. 39, No. 3, pp. 156-173). WB Saunders. doi: 10.1053/j.semnuclmed.2008.11.001.
34. Parks JS, Lin M, Grosse SD, Hinton $\mathrm{CF}$, Drummond-Borg $\mathrm{M}$ et al. (2010) The Impact of Transient Hypothyroidism on the Increasing Rate of Congenital Hypothyroidism in the United States. Pediatrics 125 Suppl 2 (Suppl 2): 54-63. doi:10.1542/peds.2009-1975F.

35. Rovet JF, Ehrlich RM, Sorbara DL. Neurodevelopment in infants and preschool children with congenital hypothyroidism: etiological and treatment factors affecting outcome. J Pediatr Psychol. 1992;17(2):187213.

36. Kooistra L, Laane C, Vulsma T, Schellekens JM, van der Meere JJ, Kalverboer AF. Motor and cognitive development in children with congenital hypothyroidism: a longterm evaluation of the effects of neonatal treatment. J Pediatr. 1994;124(6):903-9.

37. Dassie-Leite AP, Behlau M, NesiFrança S, Lima MN, Lacerda L. Phonological acquisition in children with early-treated congenital hypothyroidism: association with clinical and laboratory parameters. Codas. 2018; 30(6): e201800.

38. Elrabie Ahmed Mohamed M, Elsaayed W, Ali R, Mohamed M. Developmental Outcomes in Earlytreated Congenital Hypothyroidism: Specific Concern in Tc99m Thyroid Scan Role. International Journal of Pediatrics. 2019 Jun 1;7(6): 963143. 